Published as: Montgomery, Y.C., W.W. Focke, and C. Kelly, Measurement and Modelling of Pyrotechnic Time Delay Burning Rates: Application and Prediction of a Fast Burning Delay Composition. Propellants, Explosives, Pyrotechnics, 2017. 42(11): p. 1289-1295.

\title{
Measurement and Modelling of Pyrotechnic Time Delay Burning Rates: Application and Prediction of a Fast Burning Delay Composition
}

\author{
Yolandi C. Montgomery, ${ }^{[\mathrm{a}]}$ Walter W. Focke, ${ }^{[\mathrm{a}], \star}$ and Cheryl Kelly ${ }^{[\mathrm{b}]}$
}

\begin{abstract}
A predictive numerical model was implemented for a time delay based on the $\mathrm{Si}+\mathrm{Pb}_{3} \mathrm{O}_{4}$ system. The reaction kinetic parameters were estimated by comparing predicted surface temperature profiles with experimental data acquired with an infrared camera. Fair agreement between the modelled and measured burning rates was achieved. The burning rate is predicted to increase by $9.4 \%$ for every $50^{\circ} \mathrm{C}$ increase in ambient temperature. The core diameter was found to have a slightly larger impact on the burning rate than the wall thickness. The effect of using different wall thickness materials was evaluated and indicated that the burning rate is significantly influenced by the wall material when the thermal conductivity is increased and the volumetric heat capacity is reduced. The shape of the combustion front was found to widen with a long tail for materials with a low thermal conductivity and a narrower combustion front with a short tail for materials with high thermal conductivity. Preheating occurred for pyrolytic graphite- and diamond-based elements but no radial combustion was observed. The external heat transfer parameters (convection and radiation) did not affect the burning rate of the fast delay composition. It is concluded that the ambient temperature, volume fraction solids, molar heat of reaction, core and outer diameter are the factors that most significantly influence the burning rate of the $\mathrm{Si}+\mathrm{Pb}_{3} \mathrm{O}_{4}$ composition in long cylindrical elements.
\end{abstract}

Keywords: Burning rate; finite element modeling; time delay 


\section{Introduction}

Numerical modelling of pyrotechnic delay elements enables the study of factors that influence burning rates. Such a model was recently developed for a delay element based on the $\mathrm{Mn}+\mathrm{Sb}_{2} \mathrm{O}_{3}$ reaction [1]. The model parameters were selected such that predictions closely reproduced the surface temperature profiles measured with an infrared (IR) camera. As expected for a slow-burning composition, the temperature profiles were fully developed along the length of the lead tube-based delay element. However, this was not the case for the fast-burning $\mathrm{Si}+\mathrm{Pb}_{3} \mathrm{O}_{4}$ delay composition. Therefore, we here report on the evaluation of the utility of this model, for this system, with respect to reaction propagation, temperature profile evolution and burning rate values. The effects of delay element geometry, ambient temperature and different heat transfer scenarios on the burning rate were investigated. The modelling results are compared to other published numerical investigations as well as experimental data.

\section{Experimental Section}

\subsection{Materials}

The $\mathrm{Si}+\mathrm{Pb}_{3} \mathrm{O}_{4}$ system was employed with the fuel content fixed at 36 wt-\%. Both components were found to be $\mathrm{X}$ ray pure. The particle size distributions and BET surface areas of the powders, listed in Table 1, were determined using a Mastersizer Hydrosizer 2000 and a Micromeritics TriStar II instrument respectively.

Table 1: Powder particle size and BET surface area

\begin{tabular}{lcc}
\hline Powder & $\mathbf{d}_{50}(\boldsymbol{\mu m})$ & BET area $\left(\mathbf{m}^{2} \mathbf{g}^{-1}\right)$ \\
\hline $\mathrm{Si}$ & $1.53 \pm 0.02$ & $11.08 \pm 0.38$ \\
$\mathrm{~Pb}_{3} \mathrm{O}_{4}$ & $3.22 \pm 0.02$ & $0.74 \pm 0.08$ \\
\hline
\end{tabular}

\subsection{Preparation Methods}

The binary powder mixture was brushed five times through a $63 \mu \mathrm{m}$ sieve in order to disintegrate particle agglomerates and to facilitate proper mixing. Evaluations were performed on both aluminium and lead-drawn tubes. Lead-drawn elements were prepared by pouring $11 \mathrm{~g}$ of the mixed powder into $166 \mathrm{~mm}$ long lead tubes with inner and outer diameters of $7.0 \mathrm{~mm}$ and $11.5 \mathrm{~mm}$ respectively. The tube ends were crimp-sealed and then subjected to a ten-step drawing action on a proprietary rolling machine. This compressed and consolidated the powders. The final rolling step delivered a final outer tube diameter of $6.4 \mathrm{~mm}$. The length and core diameter depended on the packing density of the filled composition. Delay elements were prepared by cutting the rolled lead tubes into the desired lengths.

The aluminium delay elements were prepared by pressing the delay composition into aluminium tubes. Eleven increments, of about $0.2 \mathrm{~g}$ each, were compacted at a load of $100 \mathrm{~kg}$ using a hydraulic press. A schematic cross section of an aluminium delay element assembly is shown in Figure 1.

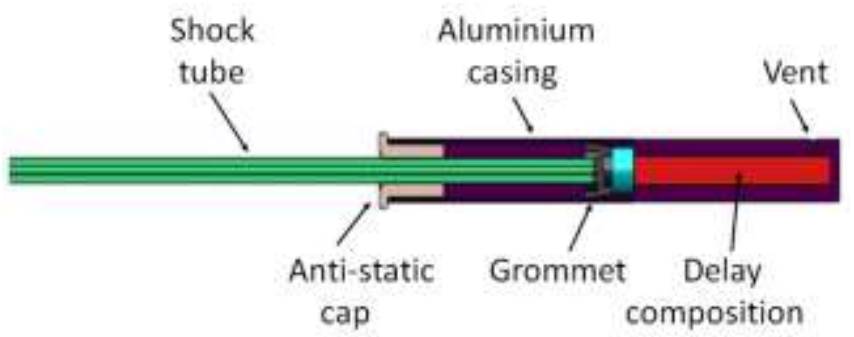

Figure 1. Aluminium delay element assembly

\subsection{Burning rate Measurements}

Temporal evolution of surface temperature profiles were captured with a Dias Pyroview 380L Compact IR camera as described previously [1]. The array measured $384 \times 288$ pixels and the frame rate was $50 \mathrm{~Hz}$. The delay element tubes were placed horizontally in front of the camera at a distance of $150 \mathrm{~mm}$. The tubes were coated with matte black high-temperature paint in order to reduce reflection and to set the emissivity close to unity. 


\section{Modeling}

\subsection{EKVI Simulations}

The thermochemistry of the $\mathrm{Si}+\mathrm{Pb}_{3} \mathrm{O}_{4}$ reaction was investigated with the EKVI Rel. 4.30 thermodynamic simulation software [2]. Product spectra and adiabatic reaction temperatures were determined as a function of stoichiometry. The simulation results, presented in Figure 2, are consistent with the redox reaction postulated on the basis of differential thermal analysis studies [3]: $2 \mathrm{Si}+\mathrm{Pb}_{3} \mathrm{O}_{4} \rightarrow 3 \mathrm{~Pb}+2 \mathrm{SiO}_{2}$

\subsection{Finite Element Model}

A 3-D finite element model of the pyrotechnic delay element was created. A full description of the model equations was reported elsewhere [1].

The thermal conductivity of $\mathrm{Pb}_{3} \mathrm{O}_{4}$ is unknown. $\mathrm{Pb}_{3} \mathrm{O}_{4}$ decomposes to $\mathrm{PbO}$ above $813 \mathrm{~K}[3 \mathrm{a}, 3 \mathrm{~b}$, 4]. Since the expected reaction temperature exceeds this value [5], the thermal conductivity of $\mathrm{PbO}$ was used instead.

The $\mathrm{Si}+\mathrm{Pb}_{3} \mathrm{O}_{4}$ reaction was assumed to occur in the following stages [3b, 3c]:

$$
\begin{gathered}
\mathrm{Pb}_{3} \mathrm{O}_{4} \rightarrow 3 \mathrm{PbO}+1 / 2 \mathrm{O}_{2} \\
\mathrm{Si}+\mathrm{O}_{2} \rightarrow \mathrm{SiO}_{2} \\
2 \mathrm{PbO}+\mathrm{Si} \rightarrow \mathrm{SiO}_{2}+2 \mathrm{~Pb}
\end{gathered}
$$

The latent heats associated with all the phase changes were accounted for via an equivalent heat capacity term as described previously [1,6]. Ignition was initiated by locating a hot copper cylinder at the one end of the element. It was $2 \mathrm{~mm}$ long and had the same diameter as the delay composition core. This ignition approach was inspired by the experiments conducted by Beck and Brown [7].

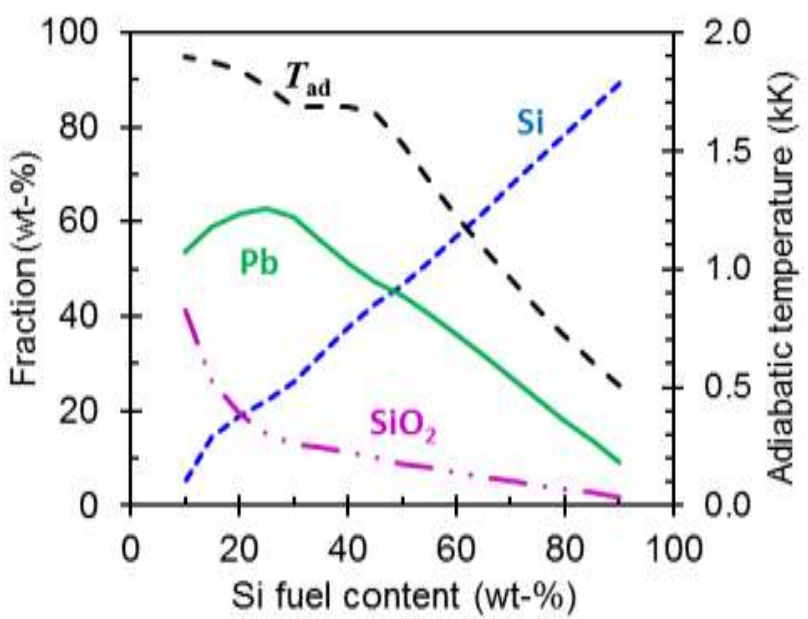

Figure 2. EKVI thermodynamic simulations: Effect of stoichiometry on the adiabatic reaction temperature and product distribution for $\mathrm{Si}+\mathrm{Pb}_{3} \mathrm{O}_{4}$.

\subsection{Meshing and Solver}

The finite element model, for the $100 \mathrm{~mm}$ long delay elements, was implemented using the COMSOL Multiphysics $4.3 \mathrm{~b}$ software suite [8]. The cylindrical symmetry of the tube made it possible to model the 3-D elements in 2-D. A fixed mesh was used because it was found that the solution time increased significantly when a moving mesh, similar to the one described for 1-D simulations by Basebi \& Thomas [9], was employed. The final mesh consisted of 98668 triangular elements. The Newtonian solver was used to find the pseudo-steady state solutions and the Jacobian was calculated at every time step to ensure convergence to a tolerance of $10^{-3}$. The parallel sparse direct linear solver was used for the transient model with row pre-ordering according to a nested-dissection multithread algorithm. 


\section{Results and Discussion}

\subsection{Reaction Propagation}

Figure 3 shows the progression of the reaction wave along the lead delay element for the $\mathrm{Si}+\mathrm{Pb}_{3} \mathrm{O}_{4}$ reaction. It compares outside surface temperature predictions of the finite element model to recordings obtained with the IR camera.

The EKVI simulations predicted an adiabatic reaction temperature of $1683 \mathrm{~K}$ for a composition containing 36 wt-\% Si. This is somewhat below the melting point of the silicon fuel (1687 K). However, Jakubko [10] calculated a higher value while Al-Kazraji [3c] reported a lower adiabatic reaction temperature.

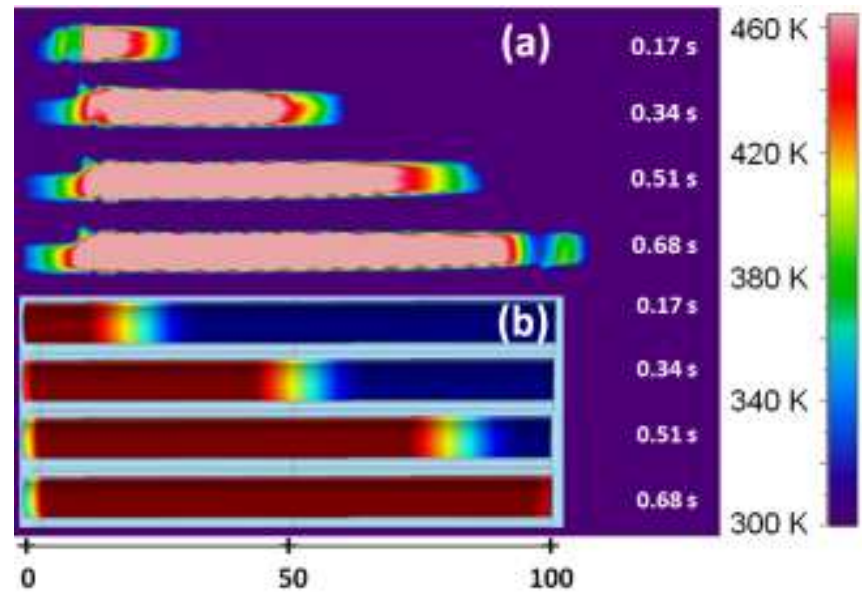

Figure 3. Surface temperatures on the outside of the element as (a) captured by the IR camera, and (b) predicted by the model for the $\mathrm{Si}+\mathrm{Pb}_{3} \mathrm{O}_{4}$ reaction wave, progressing from left to right, at various times.
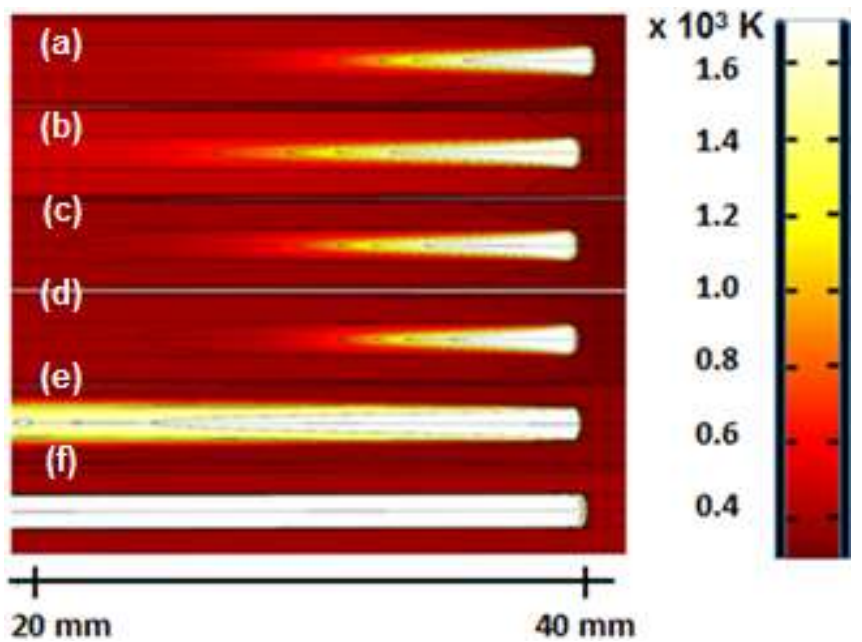

Figure 4. Predicted internal temperature distributions in delay elements made from different tube materials: (a) diamond, (b) pyrolytic graphite, (c) copper, (d) lead, (e) glass, and (f) polystyrene. The wave travels from left to right.

The shape of the reaction front is influenced by several parameters, e.g. the activation energy of the reaction, the tube wall properties, and the packing density. Figure 4 shows the effect of different tube wall materials on the internal temperature distributions in the combustion wave. The temperature isotherm surfaces have an elongated teardrop like shape. The blunt portion faces into the travel direction of the combustion wave and the sharp tail end tapers off in the opposite direction. The thinning of the tail end is caused by radial heat losses. That is why the tear drop shape elongates as radial heat loss through the tube walls decreases. Combustion proceeded nearly adiabatically in the tube with the lowest thermal conductivity, i.e. equivalent to that of polystyrene.

The temperature rise in the walls lags that in the unburned composition. The exception is the pyrolytic graphite casing. Here the isothermal contours of the reaction propagation indicate that heat is more rapidly transferred forward in the axial direction along the tube wall. This leads to a preheating effect that could cause the reaction front to propagate faster. The other materials with high thermal conductivity (diamond, copper and aluminium) did not display this behaviour. This mechanism is actually determined by a combination of the material thermal conductivity and volumetric heat capacity. The pyrolytic graphite, in addition to a high thermal conductivity, had the lowest volumetric heat capacity of the materials considered presently. Diamond has a 
somewhat higher thermal conductivity and the isothermal contours for this casing also showed slight preheating ahead of the combustion front.

A numerical study of the preheating mechanism on radial combustion was previously performed by Norgrove et al. [11]. In their simulations the tube material was assumed to be a perfect heat conductor. It was found that preheating and radial combustion was unavoidable for compositions containing $\mathrm{KMnO}_{4}$ as the oxidant because it decomposes at temperatures as low as $506 \mathrm{~K}$. Clements et al. [12] came to the same conclusion despite them using a finite conductivity for the tube walls.

In the present numerical study, the limited preheating observed with the high thermal conductivity wall materials did not lead to initiation of radial combustion. This is attributed to the relatively higher thermal stability of $\mathrm{Pb}_{3} \mathrm{O}_{4}$ compared to $\mathrm{KMnO}_{4}$. Its decomposition only commences above $873 \mathrm{~K}$. Temperatures above this value probably have to be maintained for some time before ignition would occur at the edge of the reactive column.

Directly following ignition, the reaction was fast but it then slowed down. After a distance of about $18 \mathrm{~mm}$ it settled down to a steady burning rate of $151 \mathrm{~mm} \mathrm{~s}^{-1}$. Norgrove et al. [11] and Clements et al. [12] found that the steady propagation rate is reached about $12.5 \mathrm{~mm}$ down along the burning column. However, they calculated a slower burning rate prior to this position. The difference is likely due to differences in the methods used to initiate the exothermic reaction in the calculations.

\subsection{Temperature Profiles}

The kinetic parameters $\left(n, m, E_{\mathrm{a}}\right.$ and $k_{\mathrm{o}}$ ) were determined by comparing the model predictions with the IR camerameasured temperature profiles on the outside surface of the element. Least square data regression yielded the parameter values presented in Table 2. The fitting process revealed that increasing the reaction order slows the initial temperature rise. Increasing the activation energy increased the steepness of temperature rise in the linear temperature regions. Figure 5 shows fitted surface temperature profiles over a length of the element.

Jakubko [10] assumed $n^{\text {th }}$ order kinetics for the $\mathrm{Si}_{+} \mathrm{Pb}_{3} \mathrm{O}_{4}$ system. He found values for $n$ close to unity and activation energies below $10 \mathrm{~kJ} \mathrm{~mol}^{-1}$. Although low activation energies are characteristic for diffusion-controlled reactions, those measured from thermal analysis studies are usually much higher [13]. The ignition characteristics found in the current model were similar to those of Beck \& Brown [7] even though they used an activation energy of $100 \mathrm{~kJ} \mathrm{~mol}^{-1}$.

Table 2. Best-fit kinetic parameters obtained for the finite element model for the $\mathrm{Si}+\mathrm{Pb}_{3} \mathrm{O}_{4}$ reaction.

\begin{tabular}{lcccc}
\hline Parameter & $n$ & $m$ & $E_{a}\left(\mathrm{~kJ} \mathrm{~mol}^{-1}\right)$ & $k_{o}\left(\mathrm{~m}^{3} \mathrm{~mol}^{-1} \mathrm{~s}^{-1}\right)$ \\
Value & 9 & 3 & 30 & $5.6 \times 10^{-31}$ \\
\hline
\end{tabular}

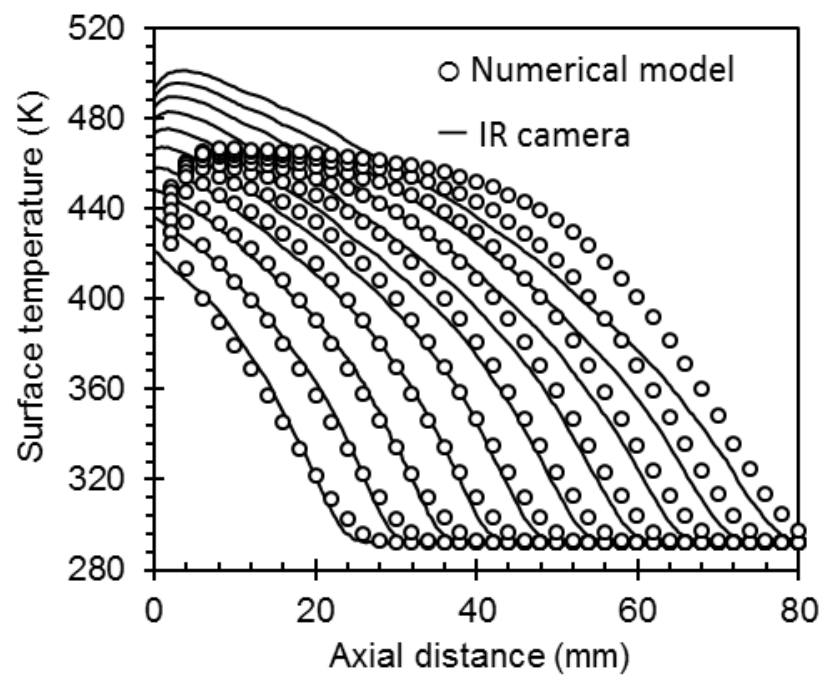

Figure 5. Surface temperature profiles in $0.04 \mathrm{~s}$ intervals as measured using the IR camera $(O)$ and modelled from the best-fit kinetics ( - ). The reaction progresses from left to right.

Figure 5 indicates fair agreement between the predictions of the model and the experimental temperature profiles recorded with the IR camera, at least at lower temperatures. The predicted temperature profiles gradually assumed a sigmoidal shape as the wave travelled along the length of the tube. The peak temperature reaches a plateau value of $466 \mathrm{~K}$. In contrast, the experimental profile did not reach a steady state and the peak temperature kept rising. The reason for this discrepancy is not currently understood. However, two other factors might be at play. Firstly, the temperature plateau values are strongly affected by the melting of the inner layer of the lead tube. 
Secondly, the solid conductive copper stopper, located at the initiation end of the model, resulted in enhanced heat loss via conduction in the axial direction.

As mentioned, the experimental temperature profiles for the fast burning delay composition were still developing. However, predicted and experimental derived burning rates agreed reasonably well with each other provided they were estimated by tracking the progression of the combustion wave at low-threshold temperature values.

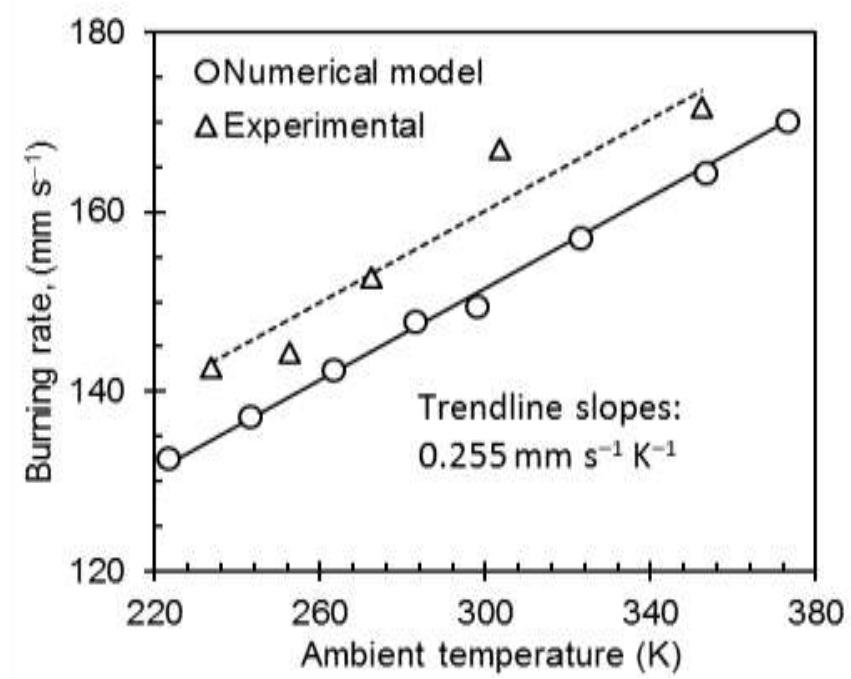

Figure 6. Average burning rate for the $\mathrm{Si}+\mathrm{Pb}_{3} \mathrm{O}_{4}$ reaction modelled and measured [14] for different ambient temperatures.

\subsection{Burning rates}

Model validity was further tested by comparing predictions, for the effects of various parameters on the burning rate, to experimental results. For example, Figure 6 compares the model-predicted effect of the ambient temperature on burning rate to the experimental findings of Jakubko [14]. The burning rate increased approximately linearly with ambient temperature. The predicted slope of ca. $0.26 \mathrm{~mm} \mathrm{~s}^{-1} \mathrm{~K}^{-1}$ is in accord with the experimental data of Jakubko [14] and Boddington et al. [15]. However, Li et al. [16] observed a somewhat lower slope for various fuel-lean $\mathrm{B}+\mathrm{Pb}_{3} \mathrm{O}_{4}$ compositions.

The effect of tube wall geometry was investigated for aluminium and lead delay elements. Figure 7 shows that the burning rate escalates with increases in both the internal and external diameters. This agrees with the experimental results of Kalombo et al. [17]. They studied the burning rate in aluminium tubes with fixed outer diameter at $6.2 \mathrm{~mm}$ but varying core diameter. These observations can be rationalised as follows. Increasing the core diameter leads to a greater mass of reactive filling per unit length and a lower specific outer surface area. Increasing the outer diameter reduces lateral heat loss. Boddington et al. [15, 18] evaluated the effect of cross sectional areas for square channels and also found faster burning rates for larger column cross-sectional areas. They concluded that the cross-sectional area is the most important factor determining lateral heat loss.

The effect of the nature of the tube wall material was also investigated for a delay element with inner and outer diameters of $2.625 \mathrm{~mm}$ and $6.4 \mathrm{~mm}$ respectively. The thermal conductivity and the volumetric heat capacity influence the thermal resistance of the tube and hence both of these parameters are expected to influence the burning rate. Combinations of thermal conductivity and volumetric heat capacity values that correspond to the properties of actual materials were modelled. The resulting response surface shown in Figure 8 indicates that an increased burning rate can be expected for tube materials with a higher thermal conductivity and a lower volumetric heat capacity. The influence of both parameters is significant for materials with very high thermal conductivities. The volumetric heat capacity has a lesser effect when low thermal conductivity materials are used. 


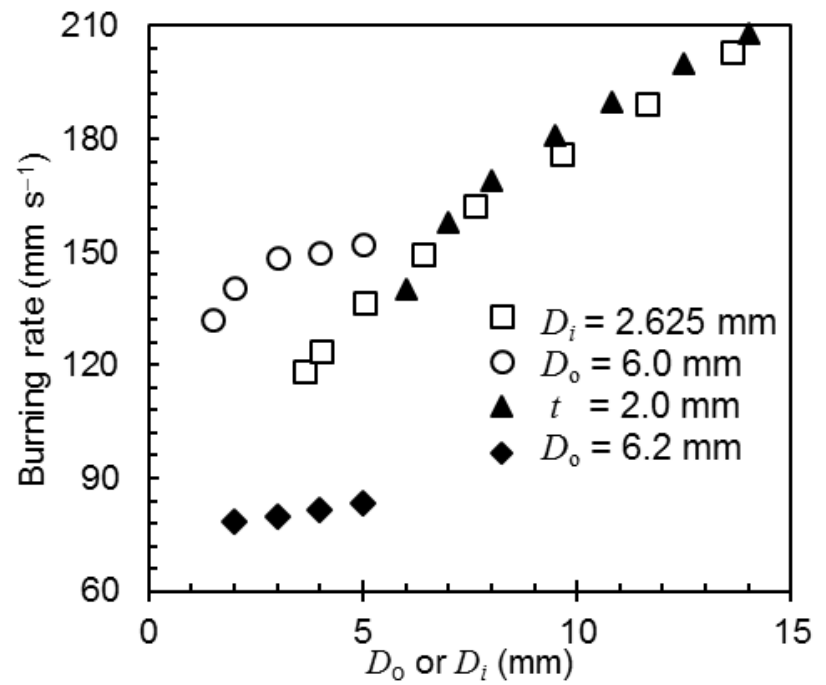

Figure 7. Model predictions for the effect of tube geometry on the burning rate for $\mathrm{Si}+\mathrm{Pb}_{3} \mathrm{O}_{4}$ composition. Lead tubes: $\square$ Fixed internal diameter with $D_{i}=2.625 \mathrm{~mm}$; O Fixed external diameter of $6 \mathrm{~mm}$. $\boldsymbol{\Delta}$ Aluminium tube with constant wall thickness of $t$ $=2 \mathrm{~mm}$. Experimental data [17] for $\mathrm{Si}+\mathrm{Bi}_{2} \mathrm{O}_{3}$ in aluminium tubes with outside diameter of $6.2 \mathrm{~mm}$.

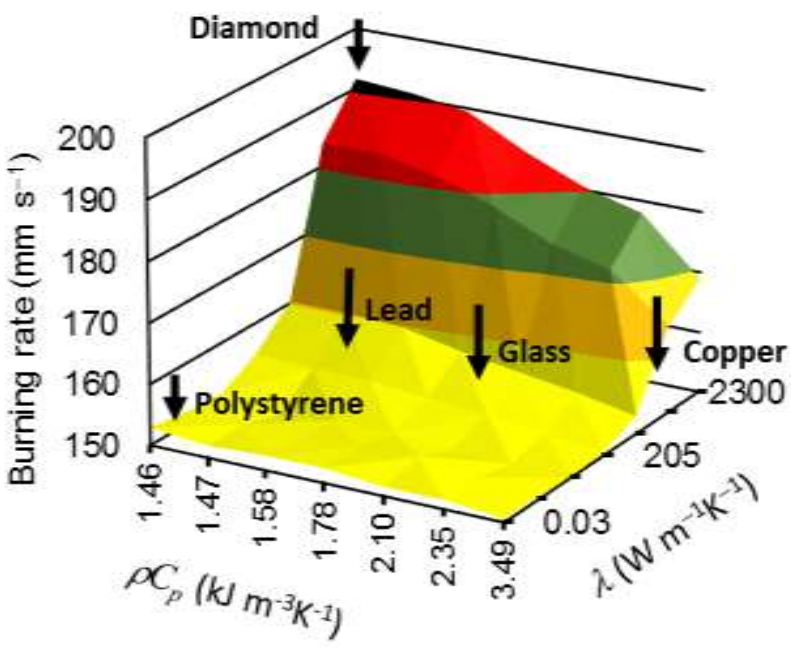

Figure 8. Average burning rates predicted from the numerical model for changes in thermal conductivity $(\lambda)$ and the volumetric heat capacity $\left(\rho C_{\mathrm{p}}\right)$ from real material properties.

The experimental results comparing aluminium to lead elements indicated only a slightly higher burning rate for aluminium tubes, consistent with the findings presented in Figure 8. Unfortunately few experimental studies addressed this issue. Kalombo et al. [17] did observe significantly slower burning rates in aluminium tubes compared to lead tubes. However, the preparation methods they used could have led to different packing densities. This exemplifies the experimental difficulties encountered when attempting comparative studies as it is very hard to control all parameters independently.

The sensitivity of the model to other heat transfer parameters was also evaluated. These were identified from the models for convection, radiation and porous media heat transfer. The results are shown in Figure 9. The external heat transfer parameters appear to have negligible impact on the burning rate. This is probably due to the fact that the reaction progresses much faster than the rate at which heat is lost from the outside of the element. On the other hand, the heat of reaction and the packing density do have a significant effect on the burning rate. This is attributed to the effect that these two parameters have on the quantity of heat generated in the reaction zone, and the rate at which it is transferred axially through the composition. The delay composition is modelled as a porous medium through which heat must be transferred axially for reaction propagation. That is why the intensity of heat generation, at a specific point inside the element, is a rate controlling factor. 


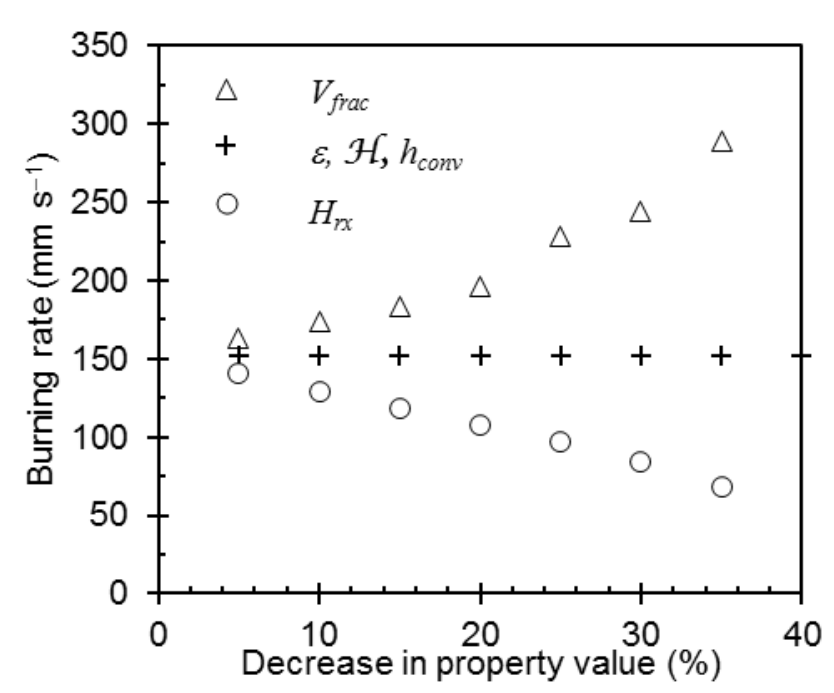

Figure 9. Sensitivity of the burning rate modelled to heat transfer parameters with decrease in property values for heat of reaction $\left(H_{r x}\right)$, volume fraction solids $\left(V_{\text {frac }}\right)$, humidity $(\mathcal{H})$, convective heat transfer coefficient $\left(h_{\text {conv }}\right)$ and emissivity $(\varepsilon)$.

\section{Conclusions}

A numerical model developed [1] for simulating time delay elements based on the $\mathrm{Mn}+\mathrm{Sb}_{2} \mathrm{O}_{3}$ reaction was adapted and applied to the fast burning $\mathrm{Si}+\mathrm{Pb}_{3} \mathrm{O}_{4}$ system. As before, model parameters were obtained by fitting predicted surface temperature profiles to those captured by an IR camera. This resulted in unusually high reaction orders for the autocatalytic reaction rate expression.

Model predictions for the burning rate were consistent with other investigations and experimental findings for the effects of ambient temperature [14], delay element geometry and the material of construction of the tube walls. Burning rates are predicted to increase with increasing core and outer diameter. High wall thermal conductivity enhances the burning rate and the effect is magnified when combined with a low volumetric heat capacity. However, the latter has virtually no effect when the tube wall has a low thermal conductivity.

The combustion front assumes a characteristic tear drop shape with the tail widening as the thermal conductivity of the tube material decreases. This is caused by the reduction in radial and axial heat losses. More rapid radial heat loss, e.g. for walls with properties equivalent to diamond or pyrolytic graphite, leads to a sharper reaction front with a thinner and shorter tail. The isothermal contours of the reaction propagation indicated that, for a pyrolytic graphite-type casing, heat is transferred laterally through the tube wall faster than through the packed composition. This causes annular preheating and results in a faster burning rate. However, radial combustion was not observed.

The external heat transfer parameters did not significantly influence the average burning rate for the fast burning composition. However, the heat of reaction and the volume fraction solids do have a significant effect on the burning rate.

The ambient temperature, core diameter, volume fraction solids, wall thickness and molar heat of reaction are the most significant factors that determine the burning rate of the pyrotechnic composition. The modelpredicted trends in the burning rate variation correlated well with the limited experimental data available in the open literature. Modelling is likely to become more accurate and more important in the future as the physical and economic considerations that limit the construction of new delay element designs are obviated. Furthermore, simulations will in future provide greater insight into the way that the reaction kinetics of the delay composition and the delay element structure interact and influence the burning rates in delay elements.

\section{Acknowledgements}

Financial support from AEL Mining Services and the THRIP programme of the Department of Trade and Industry and the National Research Foundation is gratefully acknowledged.

\section{References}

[1] Y. C. Montgomery, W. W. Focke, C. Kelly, Measurement and modelling of pyrotechnic time delay burn rates: Method and model development, Propellants, Explos., Pyrotech. (prep.201700107) 2017.

[2] Ekvi System 3.2 BeN Systems, 2004

[3] [3a] J. Jakubko, E. Cernoskova, Differential thermal analysis of the mixtures of silicon and red lead, J. Therm. Anal. 1997, 50, 511-515; [3b] S. S. Al-Kazraji, G. J. Rees, The Fast Pyrotechnic Reaction of Silicon and Red 
Lead Part 1. Differential Thermal Analysis Studies, Combust. Flame 1978, 31, 105-113; [3c] S. S. Al-Kazraji, G. J. Rees, The fast pyrotechnic reaction of silicon and red lead: heats of reaction and rates of burning, FUEL 1979, 58, 139-143.

[4] L. Sulacsik, Thermal analysis of pyrotechnical mixtures II: Study of the mechanism of the reaction of $\mathrm{MnO}_{2}+$ $\mathrm{Pb}_{3} \mathrm{O}_{4}$, J. Therm. Anal. 1974, 6, 215-220.

[5] J. T. Hedger, Factors Influencing the Pyrotechnic Reaction of Silicon and Red Lead, Propellants, Explos., Pyrotech. 1983, 8, 95-98.

[6] A. Aldushin, V. Vol'pert, V. Filipenko, Effect of reagent melting on combustion stability for gasless systems, Combust. Explos., Shock Waves 1987, 23, 408-420.

[7] M. W. Beck, M. E. Brown, Finite-element simulation of the differential thermal analysis response to ignition of a pyrotechnic composition, J. Chem. Soc. Faraday Trans. 1991, 87, 711-715.

[8] COMSOL Multiphysics 4.3b,COMSOL,3 May 2013 (https://www.comsol.com/)

[9] T. Basebi, R. M. Thomas, A study of moving mesh methods applied to thin flame propagating in a detonator delay element, Comput. Math. Appl. 2003, 45, 131-163.

[10] J. Jakubko,Combustion of the Silicon-Red Lead System. Temperature of Burning, Kinetic Analysis and Mathematical Model, Combust. Sci. Technol. 1999, 146, 37-55.

[11] A. H. C. Norgrove, A. F. Jones, J. A. King-hele,Effects of axial heat conduction in the metal wall of a detonator delay element, Combust. Sci. Technol. 1994, 97, 449-468.

[12] L. Clements, J. A. King-hele, A. F. Jones, D. C. Thomas, Some effects of axial temperature gradients in the wall of a detonator delay element, Combust. Sci. and Technol. 1995, 107, 205-221.

[13] P. G. Laye, Experimental studies of the propagation of combustion in solids [and discussion], Philos.Trans.: Phys. Sci. Eng. 1992, 339, 387-394.

[14] J. Jakubko,Pressure and temperature effects on burning rate of the silicon-red lead system, J. Energ. Mater. 1997, 15, 151-161.

[15] T. Boddington, A. Cottrell, P. G. Laye,A Numerical Model of Combustion in Gasless Pyrotechnic Systems, Combust. Flame 1989, 76, 63-69.

[16] Y. Li, Y. Cheng, Y.-L. Hui, S. Yan, The Effect of Ambient Temperature and Boron Content on the Burning Rate of the $\mathrm{B} / \mathrm{Pb}_{3} \mathrm{O}_{4}$ Delay Compositions, J. Energ. Mater. 2010, 28, 77-84.

[17] L. Kalombo, O. del Fabbro, C. Conradie, W. W. Focke, $\mathrm{Sb}_{6} \mathrm{O}_{13}$ as Oxidants for $\mathrm{Si}$ in Pyrotechnic Time Delay Compositions, Propellants, Explos., Pyrotech. 2007, 32, 454-460.

[18] T. Boddington, P. G. Laye, J. Tipping, D. Whalley,Kinetic Analysis of Temperature Profiles of Pyrotechnic Systems, Combust. Flame 1986, 63, 359-368. 